\title{
VOLVO GÁSTRICO AGUDO PERFURADO
}

\section{PERFORATED ACUTE GASTRIC VOLVULUS}

\author{
Antônio Cavalcanti de Albuquerque Martins, RCBC-PE ${ }^{1}$ \\ Miguel Arcanjo dos Santos Júnior, TCBC-PE ${ }^{2}$ \\ Alexandre Calabria da Fonte ${ }^{3}$
}

\section{INTRODUÇÃO}

Volvo gástrico (VG) é uma rotação anormal do estômago, de etiologia primária (frouxidão ou agenesia dos ligamentos gástricos) ou secundária (aderências; hérnia hiatal e outras) $)^{1}$, descrita primeiramente em 1866 por Berti em necropsia de uma mulher de 60 anos que sofrera de um quadro obstrutivo agudo. Em 1896, Berg foi o primeiro a tratar cirurgicamente, e com sucesso, um paciente com esta afecção. De acordo com o eixo de rotação classifica-se em organoaxial - eixo longitudinal, paralelo à linha imaginária cardiopilórica, sendo o mais comum (60\%) - mesentérico-axial - eixo transverso, perpendicular à linha cardiopilórica (30\%) - e tipo misto uma combinação dos outros dois ${ }^{2}$.

Um outra classificação se refere à posição que o cólon transverso assume na rotação gástrica, podendo ser anterior ou posterior ao estômago ${ }^{1}$.

A forma de apresentação crônica é assintomática ou oligossintomática, podendo ser responsável por sintomas incaracterísticos de desconforto abdominal e queimor epigástrico, considerado o mais comum ${ }^{2,3}$. O quadro agudo, representado por dor abdominal súbita, vômitos e a tríade de Borchadt (distensão epigástrica; incapacidade de passar a sonda gástrica e inúteis esforços para vomitar), é propenso à isquemia tecidual, necrose e perfuração gástrica, tendo uma evolução mais desfavorável, considerado assim uma emergência cirúrgica ${ }^{2-4}$.

Este trabalho reporta um caso de volvo gástrico agudo perfurado em um paciente de 20 anos de idade.

\section{RELATO DO CASO}

F.S.S, masculino, 20 anos, admitido no serviço de emergência do Hospital da Restauração - Recife - PE ,com história de dor epigástrica de forte intensidade há 48 horas.
A dor era constante, progressiva, inicialmente associada a vômitos alimentares, e se estendia por todo abdome superior. Havia história de ingestão de bebida alcoólica horas antes do início do quadro doloroso.

Paciente até então saudável, jamais se queixara de dispepsia, epigastralgia ou quadro similar. Não havia história de internamentos ou cirurgias prévias.

Encontrava-se com um estado geral comprometido, fácies de sofrimento, mucosas secas, hipocorado, anictérico, mal perfundido e afebril. Frequiência respiratória $=$ 38irpm; Freqüência cardíaca $=110 \mathrm{bpm}$; Pressão arterial $=95 \times 60 \mathrm{mmHg}$.

Abdome bastante tenso, extremamente doloroso à palpação, com distensão epigástrica, timpânico em loja hepática, com ruídos hidroaéreos ausentes.

Telerradiografia simples de tórax mostrava pneumoperitôneo bilateral extenso e distensão gástrica (Figura 1).

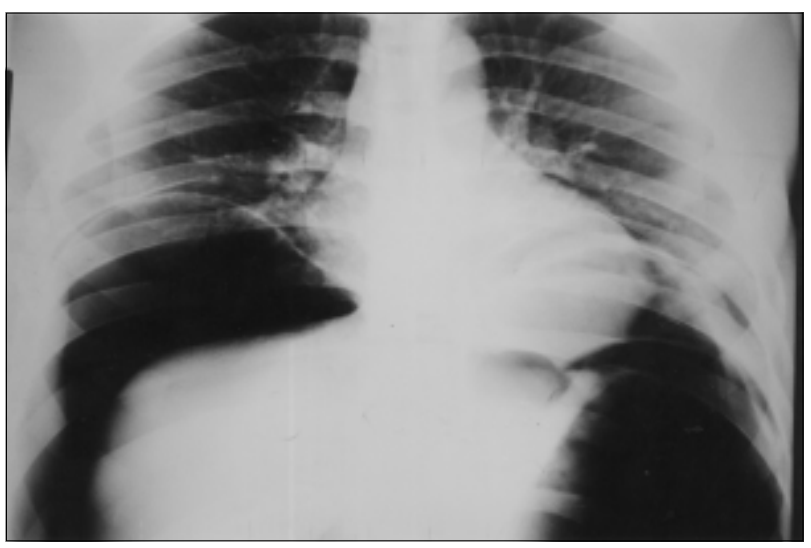

Figura 1 - Telerradiografia somples de tórax, demonstrando um pneumoperitônio bilateral extenso, com ocevação do hemidiafragma direito e distensão gástrica.

1. Residente de Cirurgia Gastroenterológica do Hospital das Clínicas - UFPE; Cirurgião geral da emergência Secretaria de Saúde/FUSAM - PE

2. Doutor em Medicina - CCS - UFPE; Cirurgião do Hospital das Clínicas - UFPE e da emergência geral do Hospital da Restauração - PE

3. Acadêmico de Medicina

Recebido em 14/05/2001

Aceito para publicação em 12/03/2002

Trabalho realizado no Serviço de Emergência do Hospital da Restauração - Recife-PE. 
O achado cirúrgico foi de uma grande quantidade $(1.000 \mathrm{ml})$ de secreção gástrica em cavidade abdominal, com estômago aumentado de tamanho e dilatado, torcido em seu próprio eixo (rotação organoaxial), com perfuração de $2 \mathrm{~cm}$ em região fúndica próximo à junção esofagogástrica (JEG) e com sinais de sofrimento tecidual que se estendia pela grande curvatura, do fundo à proximidade da transição corpo-antro.

Decidiu-se então por uma ressecção gástrica parcial incluindo parte do fundo acompanhando a grande curvatura até o terço médio do corpo gástrico com fechamento primário do estômago remanescente em dois planos.

O paciente evoluiu bem no pós-operatório, iniciando alimentação no 5o DPO, e alta hospitalar sem nenhuma intercorrência no 7o DPO.

Endoscopia e seriografia do trato gastrointestinal alto com dois meses de pós-operatório, sem alterações significativas.

\section{DISCUSSÃO}

A estabilidade do estômago é assegurada pelos ligamentos gastrocólico e gastroesplênico na grande curvatura, ligamentos gastroepático, gastroduodenal e vasculatura gástrica esquerda em sua pequena curvatura A ausência ou falha em um destes mecanismos suspensórios, bem como uma mobilidade maior do órgão por conta de uma hérnia hiatal, ou mesmo uma fixação anômala da parede gástrica secundária a aderências pós-operatórias, predispõe ao volvo gástrico ${ }^{3}$.

No relato acima não foi caracterizada a etiologia da afecção, considerada então idiopática, pois à cirurgia não havia agenesia nem frouxidão dos elementos fixadores do estômago e o paciente nunca se queixara de processos dispépticos importantes.

O volvo crônico é subdocumentado por se apresentar com sintomas comuns a outras patologias do trato gastrointestinal ${ }^{1}$. No entanto, a forma aguda se mostra como um quadro dramático de abdome agudo, uma verdadeira emergência abdominal, similar ao presente relato, raramente sobrevindo gangrena ( $5 \%$ dos volvos agudos) e perfuração, presumivelmente pelo rico suprimento sangüíneo do órgão. Quando ocorre, entretanto, a mortalidade é alta (42$56 \%)^{4}$, daí a importância do diagnóstico e tratamento rápido.

O diagnóstico da forma crônica é realizado durante investigação de dor ou desconforto abdominal alto, por exame contrastado e/ou endoscopia. Esta forma deve ser diferenciada da cólica biliar, úlcera duodenal crônica e gastrite $^{3,4}$. O volvo agudo é identificado fortuitamente na laparotomia exploradora ${ }^{3}$, apesar de um grande nível hidroaéreo em abdome superior, sem qualquer outra bolha gasosa abdominal na telerradiografia simples de abdome, ser bastante sugestivo de volvo agudo organoaxial ${ }^{5}$.

O tratamento para o volvo crônico é indicado por recorrência da sintomatologia, sendo feito por gastropexia que pode ser realizada por via laparoscópica.

No quadro agudo sem complicação (isquemia, sangramento ou perfuração) pode ser feita a redução da torção por via endoscópica e laparoscópica combinadas. $\mathrm{Na}$ vigência de complicações é indicada laparotomia com gastrectomia parcial ou total, desbridamento e rafia primária da perfuração ou apenas redução do volvo com gastropexia, a depender da viabilidade do órgão.

A gastrectomia total tem maior morbimortalidade, além das eventuais síndromes pós-gastrectomias e distúrbios nutricionais, devendo ser reservada para casos com comprometimento extenso e quase total da vascularização gástrica.

Neste relato a ressecção gástrica parcial não comprometeu a evolução do paciente no pós-operatório, estando o mesmo no momento livre de qualquer sintomatologia. Um déficit de cianocobalamina (Vit. $\mathrm{B}_{12}$ ) talvez seja a única seqüela desta ressecção fúndica, a qual, se ocorrer, se expressará após dois a três anos, devido à sua reserva hepática. Esta ressecção gástrica atípica também pode determinar refluxo gastroesofágico e esofagite.

\begin{abstract}
The authors report a case of acute gastric volvulus in a 20-year-old male, complicated by perforation near the gastroesophageal junction and generalized peritonitis. This is an uncommon and potentially lethal conditon although our patient has been handled successfully with a partial gastrectomy.
\end{abstract}

Key Words: Acute gastric volvulus; Gastric perforation; Peritonitis. 


\section{REFERÊNCIAS}

1. Zinner M, Schwartz S, Ellis H. Diverticula, Volvulus, Superior Mesenteric Artery Syndrome, and Foreign Bodies. In Maingot's Abdominal Operations. $10^{\circ}$ Edição. Editora Appleton \& Lange, 1997, Vol.02 pp. 921-926.

2. Farag S, Fiallo V, Nash S, Navab F. Gastric perfuration in a case of gastric volvulus. Am J Gastroenterol, 1996, 91 (9): 1863-1864.

3. Lopasso FP, Mello JB, Garrido AB, Rodrigues JJG, Raia A. Volvo Gástrico Considerações sobre 22 casos. Rev Ass Med Brasil, 1981, 27(4): 121-126.

4. Grendell HJ. Miscellaneous Disorders of the Stomach \& Small Intestine. In: Grendell HJ, McQuaid R, Friedman LS. Current Diagnosis \& Treatment in Gastroenterology. Editora Appleton \& Lange, 1996, p. 363.
5. Andiran F, Tanyel FC, Balkanci F, Hiçsonmez A. Acute abdomen due to gastric volvulus: diagnostic value of a single plain film radiograph. Pedriat Radiol, 1995, 25: 240.

Endereço para Correspondência:

Antonio Cavalcanti de Albuquerque Martins

Rua Deputado Pedro Pires Ferreira, 325, apto 1601 Jaqueira 52050-480 - Recife - PE

E-mail:Acam@elogica.com.br 